\title{
Awareness and Adoption of Paddy Farmers in Buttala Sri Lanka to Golden Rules of Pesticide Usage
}

Katukurunda Gamage S.C. ${ }^{1}$, Abeysinghe L.S. ${ }^{2}$, Dolamulla Kankanamge C.D. ${ }^{3}$ and Ranepura Hewage T. C.N. ${ }^{2}$

\author{
${ }^{1}$ Department of Animal Science, Faculty of Agriculture, University of Ruhuna, \\ Kamburupitiya, Sri Lanka \\ ${ }^{2}$ Department of Agricultural Economics, Faculty of Agriculture, University of Ruhuna, \\ Kamburupitiya, Sri Lanka \\ ${ }^{3}$ Department of Crop Science, Faculty of Agriculture, University of Ruhuna, \\ Kamburupitiya, Sri Lanka \\ *shan.caltex@gmail.com
}

\begin{abstract}
Pesticides are widely used in agricultural production to prevent or control pests, diseases, weeds and other plant pathogens in an effort to reduce or eliminate yield losses and maintain high produce quality. There is a higher risk in pesticide usage due to hazardous nature of them; hence, safety measures should have practiced to minimize the threats. Especially in Paddy cultivation, various types of pesticides were applied during its various growing stages as from the seedling to harvest. The objective of the study was to investigate the awareness and adoption on "Golden Rules" which are (1) exercise caution at all times (2) careful reading and understanding of label before use (3) practicing good personal hygiene (4) take care of and maintain application equipment and (5) wear appropriate personal protective clothing and equipment, in the area of Buttala, Sri Lanka at three levels as "High" "Moderate" and "Low". A field survey which based on pre tested questionnaire was carried out by using randomly selected 50 Paddy farmers without considering their age classes, education and economic status etc. to find out the awareness and adoption to "Golden Rules" in five operations (in the operations of pesticide buying, transportation, storage, application and disposal). Survey results revealed that the farmers of Buttala did not aware on "Golden rules" and their adherence to "Golden Rules" is not satisfactory. Moreover, "Moderate" level of awareness and adoption on the processes of buying $(52,48 \%)$ and storage $(51,52 \%)$ but "Low" awareness and adoption on transportation (51, 52\%), application (48, 48\%) and disposal $(52 \%, 50 \%)$ seen from total number of farmers $(n=50)$. The risk of contamination was high due to careless transportation, application and disposal because of "Low" awareness and adoption for those processes therefore immediate awareness programs are required. According to survey findings the pesticides were applied heavily because of the lack of knowledge and elevated pest and disease problems, therefore there was a threat to environment mainly from application and disposal by contaminating water sources of the area. Promoting of extension services, farmer credit facilities to buy safe equipments, directing farmers towards integrated pest management and activate regulations on pesticide usage are needed to protect public from hazardous agrochemicals. Furthermore, this is a matter of concern to overcome the hazardous problem of pesticides use before it is ecologically and socially getting worst in the future.
\end{abstract}

Keywords: Awareness, Adoption, Golden rules, Pesticides, Contamination

Proceedings of the International Forestry and Environment Symposium 2013 of the Department of Forestry and Environmental Science, University of Sri Jayewardenepura, Sri Lanka. 